\title{
Multi-storey wooden house building
}

\author{
Alexey Slavin ${ }^{1, *}$, Sevada Grigoryan ${ }^{1}$, Egor Popandopulo ${ }^{1}$, Aleksandra Balaeva ${ }^{1}$ \\ ${ }^{1}$ Moscow state University of civil Engineering, Yaroslavskoe shosse, 26, Moscow, 129337, Russia
}

\begin{abstract}
The study solves the following tasks: analysis of construction technologies that prevent environmental pollution, the development of wooden housing construction objects, the wooden housing construction strategy and the term of its implementation, and a comparison of Russian and international experience in the development of wooden housing construction. According to the results of the study, the technology of construction of multi-storey wooden houses can be a very promising component for improving the quality of life of the population, moreover, a priority from an economic point of view and effective for the development of facilities that contribute to the improvement and compliance with environmental safety requirements. The most effective type of construction in this industry is the construction of LVL timber and CLT panels. Minimum construction time, environmental friendliness and availability of this technology will accordingly improve the living conditions of the population and thus the overall environmental condition.
\end{abstract}

\section{Introduction}

The set of environmental problems is characteristic of any territory in which enterprises of various industrial nature and population are concentrated. To the greatest extent, these problems are manifested in the conditions of the city, and the composition and their severity depend on many factors. This can include:

- The scale of the city - its area, composition and population;

- Features of the building-its number of storeys, density, location in relation to the elements of the terrain;

- Reliability and condition of engineering networks and communications that provide the city with electricity, water, as well as communication systems providing the necessary information, etc.;

- The nature and the extent of emissions of substances that pollute the atmosphere, water sources and soils of the urban area.

Professional construction organizations often see the tightening of environmental requirements as something completely unnecessary that increase the level of construction costs. In our time of development of the construction industry, when society has moved away from natural building materials and has turned to artificially created, the taken measures may well be relevant and justified.

${ }^{*}$ Corresponding author: slavinam@mgsu.ru 
Enterprises that are engaged in the production of building materials emit an enormous amount of waste, dust, and combustion products into the environment. Construction needs are provided by cars and vehicles, the environmental safety of which often does not meet some requirements. To be honest, the construction work itself is often carried out without observing any measures to preserve the landscape and the environment in general. That is why the requirements of ecology during construction have recently become tougher, more and more attention is being paid to such an issue as eco-development - the construction of eco-houses and so-called active houses, which is usually denoted by the term "green building". One of the variants of this construction is multi-storey wooden housing construction with the aim of improving the ecological state of the environment. Wood is an eco-friendly material, the use of which in construction not only provides buildings with the necessary tightness and makes them visually attractive, but also improves the quality of indoor air while allowing for greater flexibility in planning solutions.

Thus, the relevance of this scientific work is to create a promising and environmentally justified activity on the example of the construction of multi-storey wooden houses in order to improve the ecological state of the environment.

This article discusses the key study tasks:

- analysis of construction technologies that prevent environmental pollution;

- development of wooden housing construction objects;

- the effect of the strategy of wooden housing and the timing of its implementation;

- comparison of Russian and international experience in the development of the construction of wooden housing facilities.

\section{Research methods}

A study, as a result of which it will be possible to draw a conclusion on the rationality and development prospects of construction in this direction, should be conducted to determine the need for the development of wooden multi-storey housing construction in order to improve the ecological state.

This article uses data analysis of the total number of wooden houses, their percentage in different countries, as well as the advantages of wood compared to other materials as a method for the study. According to the published OECD Green Growth Indicators 2017 report, progress in improving the efficiency of using natural resources and reducing the burden on the environment in the world is too slow. Moreover, the report notes that the level of air pollution remains dangerously high. In particular, less than 1/3 of OECD countries comply with WHO standards. The level of emissions of harmful substances in Russia is significantly higher than in many large countries, which leads to increased risks for the population. Based on this, the Russian Federation is an example of a study. It is also necessary to analyze the possibility of using wood as a building material without causing damage to the ecological environment. We should make an assessment of the countries' provision of this type of building material or the possibility of purchasing wood for use in construction.

\section{Research results}

The research results show that all over the world work is underway to develop systems and technologies that implement environmentally friendly and reliable material - wood. An 
example of a study in the article is Russia and is compared with international countries. According to the Association of Wooden House Building (WHA) of the Russian Federation, the world experience of low-rise wooden construction is shown in the diagrams:

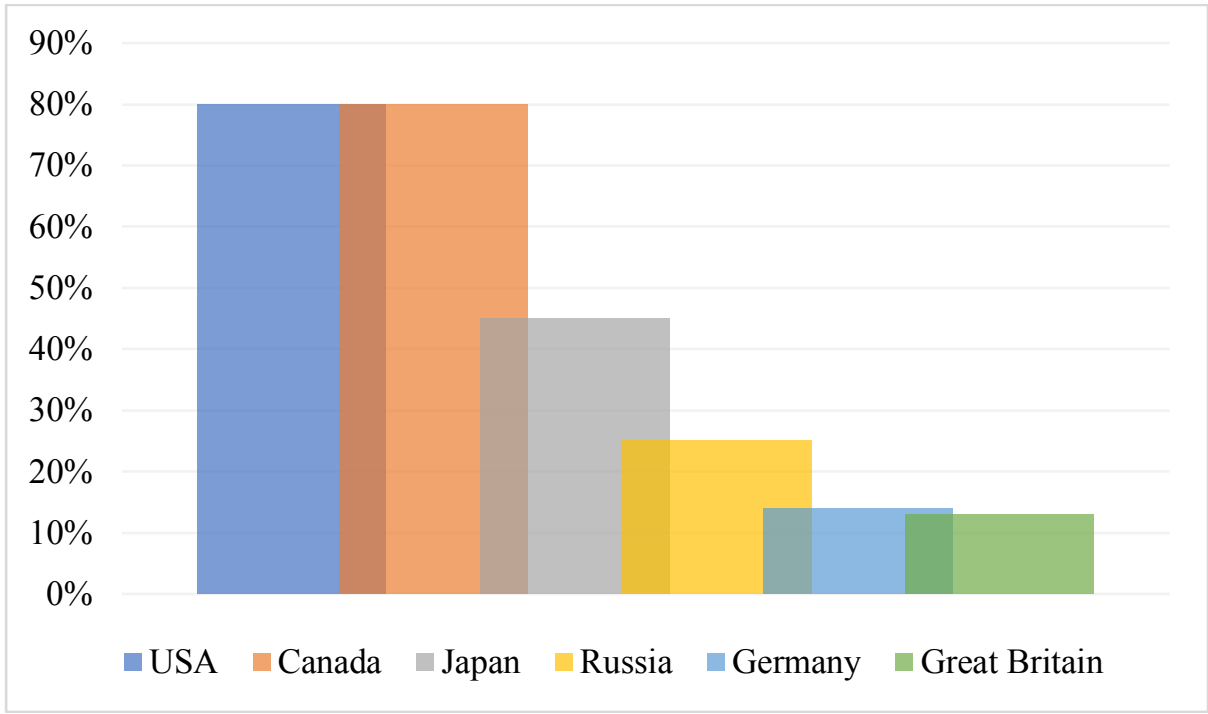

Fig. 1. Diagram of the total volume of wooden low-rise housing construction by country.

After analyzing the data presented in the diagram, we can conclude that in Russia the share of use of products for low-rise wooden housing construction is lagging behind the indicators of other countries. In the Russian Federation traditionally exclusively low-rise individual housing is developed, but even in comparison with other countries the share of construction of low-rise wooden houses is in 2 or more times less and comparing the stocks of wood Russia is one of the leaders. Meanwhile, in the world the development in the field of wooden construction does not stop and multi-storey wooden house building is actively developing along with low-rise building.

It would seem that there was nothing special in wooden house building. There are a number of advantages of wood as a building material to answer this question:

- Environmental friendliness - development of settlements in landscape zones and high utilization of wood in production;

- Renewable resource;

- Construction time of wooden houses is much faster;

- Lightweight of construction - 6 times lighter than concrete;

- Seismic resistance, static strength in all directions;

- Non-shrinkage, non-freezing, impermeability of walls and joints

- Ability to resist high temperatures for a long time without deterioration of the strength characteristics.

The construction of high-rise residential buildings and business centers which are made of wood is a promising direction, which is gaining increasing popularity in the countries of America and Europe. The technologies of wooden housing construction are constantly being improved, and the fact that building from wood is profitable, reliable, fast and safe is becoming obvious. Methods for the construction of wooden houses are developing and do 
not stand still. There are new opportunities and records are setting for the construction of multi-storey buildings using LVL glued timber and CLT wood panels. Structures that are made of LVL timber are used as vertical and horizontal elements of the bearing frames of buildings. This technology is a multi-layered sheets of coniferous wood. The fiber layers are arranged in parallel, the thickness of each of the layers is about $3 \mathrm{~mm}$. The span of beams, which does not require supports, from a LVL beam can reach $36 \mathrm{~m}$, and farms - 42 $\mathrm{m}$ and more. This bar does not shrink, and also remains geometrically unchanged throughout its service life. Unlike conventional wood, LVL technology is not affected by microorganisms, is not deformed due to dampness, and is resistant to chemical aggression. Modern manufacturing technologies provide a high degree of availability of building structures, and the assembly of a wooden frame at the construction site is performed by analogy with the installation of pre-fabricated buildings from steel. The technology of CLT plates and panels is a composite material produced by the method of cross-gluing wood layers. This technology is used as floor slabs, enclosing structures and building coatings. The construction of CLT plates is distinguished by lightness, fire safety, high strength, as well as heat and sound insulation. Currently CLT plates are available in thicknesses from 60 to $400 \mathrm{~mm}$. The installation speed of the presented wooden structures is significantly higher compared with other construction technology, and is due to the technical ability to transport finished blocks and modules to the work site. Modern equipment is capable of producing CLT panels with a length of up to $24 \mathrm{~m}$ and a width of up to $3.5 \mathrm{~m}$, which makes it possible to install the building envelope of the entire floor of the building in one go.
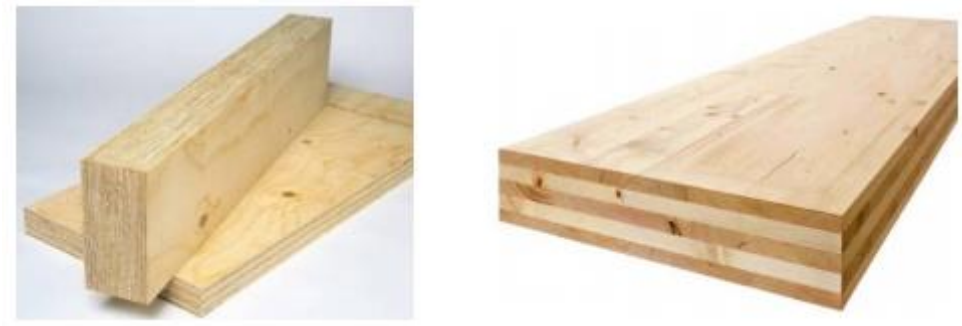

Fig. 2. LVL timber and CLT panels.

An 18-storey, 53-meter-high Brock Commons dormitory in Canada which is made of wooden structures can be considered as an example. The Brock Commons building was erected in 40 days at a speed of assembly of one floor in two working days, which is about four months faster than with traditional construction methods. At the same time, the construction process was so environmentally efficient that it can be equated in scale to the disappearance from city roads of about 500 cars for a whole year. About 22,000 tons of timber was used to build the Brock Commons. But wood is a renewable resource; forests of Canada and America renew this wood in just six minutes. 

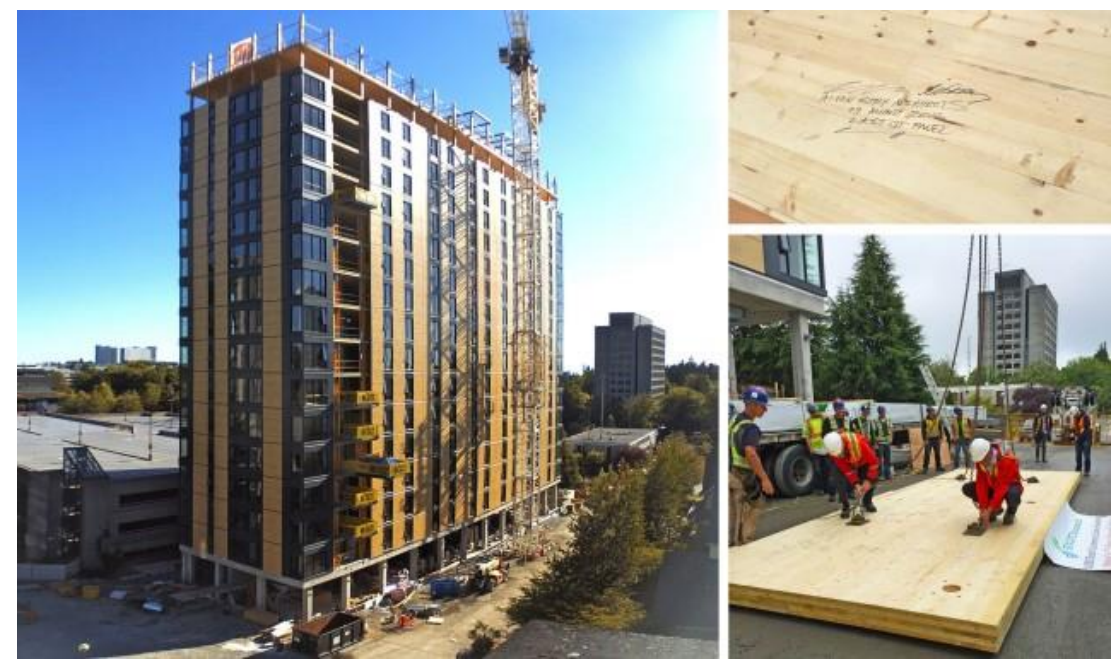

Fig. 3. Brock Commons Building in Canada.

The Russian Federation has $23 \%$ of the world's forest resources. This indicator provides an opportunity for development in the field of wood construction, but not everything is as simple as it seems. It is necessary to solve a number of key problems that hamper the wider use of wooden housing construction in the Russian Federation to enable the development of multi-storey wooden construction. Among them:

- outdated standards for wooden structures;

- lack of building codes for multi-storey buildings (over 3 floors);

- imperfection of the regulatory framework in terms of fire safety.

According to The Environmental Performance Index for 2018, Russia is in 52nd place with an environmental index of 63.79 in the ranking of eco-friendly countries in the world. For comparison, we present a graph with the environmental indexes of international countries: 


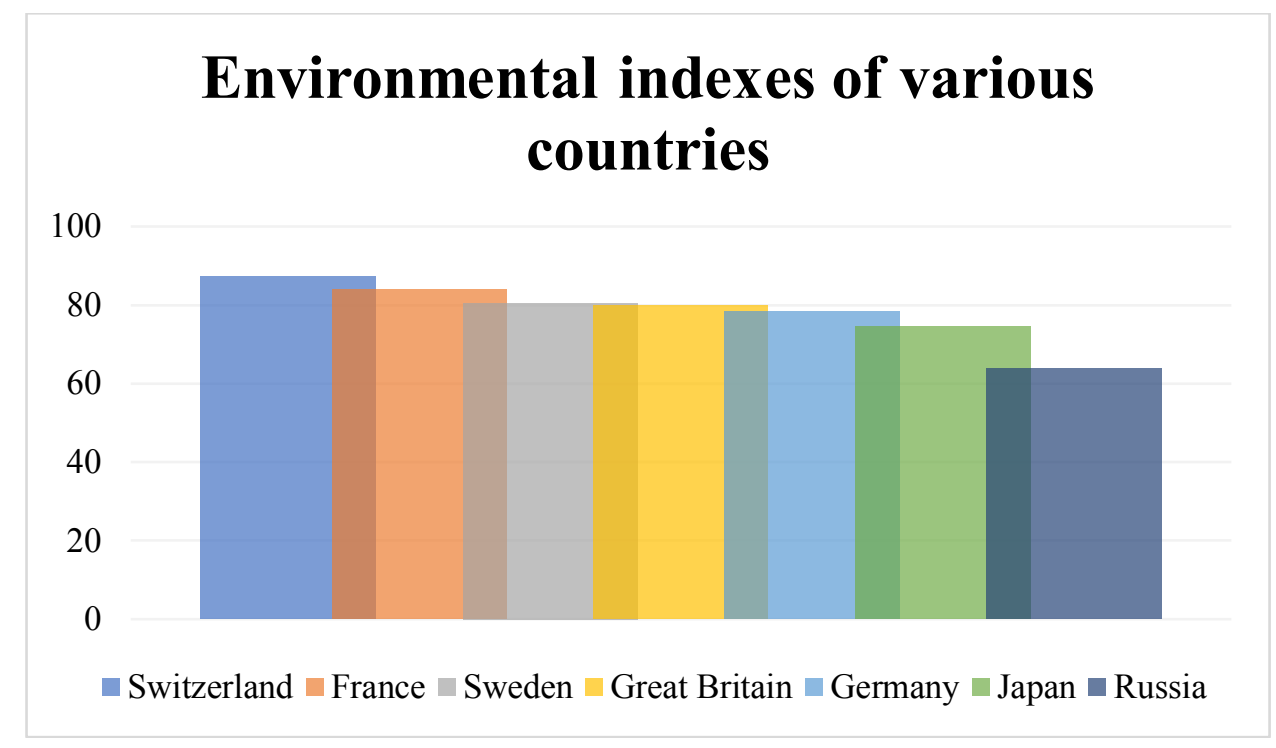

Fig. 4. Environmental indexes of various countries.

\section{Conclusion}

Ecology is an integral part of our life. Modern human society needs to recognize the participle of the ecosystem. The main task at this stage of life is to prevent the aggravation of the general environmental situation, to treat environmental problems and requirements with the utmost responsibility. Based on the foregoing, currently systems are being actively developed that improve the ecological state in general.

In this article studies were conducted with the main goal - to improve the ecological state of the environment. The object of research was the technology of construction of multi-storey wooden housing. Building wooden houses will help to improve the ecological state of the environment as a whole and to provide comfortable living conditions for the population. This type of construction will ensure the rational use of wood as a building material. The prospects of the presented direction are in the ecological use of wood in construction.

Based on the results of the study wooden multi-storey housing construction is gradually developing and progressing in countries with a high environmental index. Despite the fact that the Russian Federation has extensive resources in terms of forestry, the construction technology of multi-storey wooden housing construction is not receiving proper attention today. According to the rating of the most environmentally friendly countries Russia is not included in the TOP - 50. The technology of multi-storey wooden construction will help the Russian Federation to increase the environmental index, thereby improving the living conditions of the population. The technology described in this article has already earned interest in countries such as the USA, Canada, and Sweden, Finland and others, which determines the future prospects for improving the ecological state of the environment. 


\section{References}

1. D. Lazarevic, P. Kautto, R. Antikainen, Forest Policy and Economics (2019)

2. F. Domhagen, P. Wahlgren, Energy Procedia 132, 873-878 (2017)

3. A.Toppinen, A. Röhr, S. Pätäri, K. Lähtinen, R. Toivonen, Journal of Forest Economics 31, 3-10 (2018)

4. J.W.G. Van De Kuilen, A. Ceccotti, Zhouyan Xia, Minjuan He, Procedia Engineering 14, 1621-1628 (2011)

5. P. Wei, H. Long-hua, Procedia Engineering 11, 355-359 (2011)

6. F. Asdrubali, B. Ferracuti, Building and Environment 114, 307-332 (2017)

7. A. Ruuska, T. Häkkinen, Energy Procedia 96, 190-201 (2016)

8. K. Buka-Vaivade, D. Serdjuks, V.Goremikins, Procedia Engineering 172, 1212-1219 (2017)

9. M. Qu, P.Pelkonen, L. Tahvanainen, Journal of Cleaner Production 31, 100-105 (2012)

10. J. Mehr, C. Vadenbo, B. Steubing, S. Hellweg, Resources, Conservation and Recycling 131, 181-191 (2018)

11. L. Wang, A. Toppinen, H. Juslin, Journal of Cleaner Production 65, 350-361 (2014)

12. J. Malesza, C. Miedziałowski, Procedia Engineering 172, 701-705 (2017)

13. Y. Tonooka, H. Takaguchi, K. Yasui, T. Maeda, Energy Procedia 61, 1634-1637 (2014)

14. K. Goda, H. Yoshikawa, Soil Dynamics and Earthquake Engineering 48, 1-14 (2013)

15. Y. Gerasimov, T. Karjalainen, Biomass and Bioenergy 35(5), 1655-1662 (2011)

16. D. Sanscartier Pilon, A. Palermo, F. Sarti, A. Salenikovich, Soil Dynamics and Earthquake Engineering 117, 234-244 (2019)

17. E.L. Schmidt, M. Riggio, A.R. Barbosa, I. Mugabo, Building and Environment 148, 609-622 (2019)

18. K.S. Sikora, D.O. McPolin, A.M. Harte, Construction and Building Materials 116, 141-150 (2016)

19. D. Sanscartier Pilon, A. Palermo, F. Sarti, A. Salenikovich, Soil Dynamics and Earthquake Engineering 117, 234-244 (2019)

20. D. Sanscartier Pilon, A. Palermo, F. Sarti, A. Salenikovich, Soil Dynamics and Earthquake Engineering 117, 234-244 (2019) 